Pak. j. sci. ind. res. Ser. B: biol. sci. 2017 60(1) 49-62

\title{
Review
}

\section{Control of Avian Coccidiosis: Present and Future Strategies for Natural Alternatives of Therapeutics}

\author{
Muhammad Jamil ${ }^{\mathrm{a}}$, Muhammad Mansoor ${ }^{\mathrm{a} *}$, Arsalan Khan ${ }^{\mathrm{b}}$, \\ Rizwan ul Haq ${ }^{\mathrm{b}}$ and Fawad Anwar ${ }^{\mathrm{a}}$ \\ ${ }^{a}$ Arid Zone Research Centre-PARC, Dera Ismail Khan - 29050, Pakistan \\ bepartment of Parasitology and CMS, University of Agriculture, Faisalabad-38040, Pakistan
}

(received February 29, 2016; revised June 9, 2016; accepted July 12, 2016)

\begin{abstract}
Avian coccidiosis has great economic impacts on poultry enterprise. Coccidiosis is caused by Eimeria species mostly affecting epithelium of the bird's intestines causing enteric problems. Prominent clinical outcomes are bloody diarrhoea, poor FCR, weight gain and growth rate with high morbidity and mortality rate. For the control of coccidiosis various strategies have been adapted including chemical agents and feed additives. But due to their repeated use, drug resistance to Eimeria species emerged thus badly affecting their efficacy. Moreover, these chemical agents have adverse effects on bird's health and meat quality. Therefore, alternatives are used nowadays including natural and herbal products having the desired efficacy without harmful effects. Natural products and their anticoccidial activity have been reviewed in this study. This group comprises herbal extracts, fatty acids, fungal extracts, probiotics and immune response immunomodulators with proven anticoccidial activity. Additionally, poultry industry and economic cost of coccidiosis as well as classical strategies used in the control of avian coccidiosis are also reviewed.
\end{abstract}

Keywords: coccidiosis, natural alternatives, poultry, probiotics, herbal extracts

\section{Introduction}

Commercial poultry farming is one of the most flourishing industries in the world and it provides the cheapest source of animal proteins to human beings (Ahmad et al., 2011). In Pakistan, out of total meat production, $19 \%$ is contributed by poultry (Ahmad et al., 2010). Poultry farming is increasing day by day at commercial level however, due to certain diseases like coccidiosis, its development is affected in Pakistan and other countries of the world (Saima et al., 2010). Coccidiosis is mainly caused by single celled protozoan of genus Eimeria of phylum Apicomplexa with complex life cycle. In commercial poultry farming, the incidence of coccidiosis ranges from 5 to $70 \%$ (Du and $\mathrm{Hu}, 2004$ ). Eimeria species mostly affect the epithelial cells of bird's intestine, resulting in enteric problems leading to bloody diarrhoea, poor growth rate and high mortality with heavy economic losses up to three billion dollar per annum worldwide (Dalloul and Lillehoj, 2006). So far seven species of genus Eimeria (E. mitis, E. maxima, E. acervulina, E. necatrix, E. brunetti, E. tenella and E. praecox) have been identified that are responsible *Author for correspondence; E-mail: joyadkpk@googlemail.com for coccidiosis in chickens by residing in different parts of their intestines. The most devastating specie is E. tenella that causes ceacal coccidiosis in chickens. Ceacum is the predilection site for E. tenella sporozoites that invades its mucosa through villi of epithelial cells and results in severe damage to epithelium, reduced weight gain, blood in feaces, poor feed efficiency and ultimately death of birds that leads to heavy economic losses (Zaman et al., 2012). Sub-clinical form of avian coccidiosis manifests as immunosuppressant in the birds that result in outbreak of secondary bacterial diseases. During rainy seasons, there is high incidence of coccidiosis (Etuk, 2010). The hot and humid weather positively hastens prevalence of disease by providing favourable conditions to the infective oocyst.

Various strategies in the past have been adopted to overcome avian coccidiosis including use of synthetic chemicals and anticoccidial feed additives. However, with the passage of time and repeated use of these drugs there is emergence of anticoccidial drug resistance in Eimeria species (Abbas et al., 2012). Along with this Nogueira et al. (2009) has also reported that harmful effects of these chemicals on bird's health status and 
consumption of affected meat by humans are the major constraints. Another technique for the control of coccidiosis is the use of live vaccines but this practice may lead to development of clinical disease in the broiler under poor management (Chapman, 2000). Owing to increasing drug-resistant parasite strains, the use of these chemical agents proved ineffective and there is need of time to introduce alternatives for the control of disease (Abbas et al., 2012; Tacconelli, 2009). Resistance development in target parasites, high cost, and toxic effects of chemotherapeutic drugs are the main constraints. Therefore, for the prevention of coccidiosis, current circumstances demands alternatives. Natural and synthetic biological compounds considered as appropriate agents (Patwardhan and Gautum, 2005), to sustain bird health without affecting performance. Plant based biological active compounds are thought to be promising candidates due to their availability and powerful efficacy with no or minimal residual effect in consumers (Patwardhan and Gautam, 2005). To cure health related issues almost $64 \%$ of human population use plant based drugs worldwide (Farnsworth, 1999).

During last decade, various authors have reported that plant and herbal products have protective and therapeutic effects against experimental coccidial infections in birds (Lorrain et al., 2010; Nweze and Obiwulu, 2009). It has been reported that $50 \%$ synthetic drugs have been made from compounds of plants. In this regard, one of the important source is cereals. In humans and other animal models, studies have shown that dietary cereal fibres may have a great effect on different physiological parameters. Cereals based carbohydrates are mainly reported as antitussive, antioxidant, antimutagenic, antiinflammatory, anti-cancerous and immunomodulators (Zhou et al., 2010). Cereals, fungi and yeast cell wall contain $\beta$-glucans as principle structural components with molecular weight $2000 \mathrm{kDa}$ approximately. These polysaccharides enable the host to develop resistance against viral, parasitic, fungal and bacterial diseases by enhancing immune system, lysosomal enzyme activity, phagocytosis and IL-1 production (Estrada et al., 1997). Botanicals may act as best and safe alternative source to anticoccidial drugs for the prevention of coccidiosis (Abbas et al., 2012). A variety of botanicals including Triticum aestivum, Hordeum vulgare, Emblica officinalis, Aloe vera and Avena sativa have shown effective biological responses. Oryza sativa also known as Asian rice, belonging to family Poaceae is an annual plant, which has shown immunostimulant effect through increased allergic reactions, inhibited mast cell degradation in rat (Ghatak and Panchal, 2012; Oka et al., 2010), increased nitric oxide, TNF- $\alpha$ and interleukins in murine macrophages (Park et al., 2013) as well as increased lymphocytic proliferation, TNF- $\alpha$ and interferon- $\gamma$ (Ghoneum and Jewett, 2000). The denatured bran of this plant results in arabinoxylan by means of enzymatic hydrolysis, a polymer of xylose and arabinose (Ghoneum, 1998). Alternatives are not only natural products but they also contain valuable molecules to which resistance has not yet developed. Herbal and medicinal plants, fungal extracts and probiotics could have additional significant benefits such as palatability, low cost, low toxicity and non-residual properties (Table 1-3). Currently interest has been developing in the use of these natural products to reduce the chances of coccidiosis.

Review of literature. Favourable results have been obtained by using natural alternatives in avian coccidiosis as described in the following review literature:

Antioxidants. Fats and oils. Deficiency of vitamin A in poultry increases susceptibility to coccidiosis and other enteric infections. Alterations in intraepithelial lymphocytes due to vitamin A deficiency increase susceptibility of birds to coccidiosis (Dalloul et al., 2003). Fats contained higher concentrations of linolenic acid, eicosapentanoic acid and reduced severity of coccidiosis in young broilers. Feed supplemented with $10 \%$ linseed oil, $10 \%$ flax seed oil and 10\% fish oil markedly reduced ceacal lesions. Fats decreased parasitic infestation and provided immunity against Eimeria (Allen et al., 2000). Antioxidants have been divided into two categories; i.e., fat soluble (Vitamin $\mathrm{E}$ and carotenoids) and water soluble (Vitamin $\mathrm{C}$, uric acid, glutathione and lipoic acid). Fat soluble antioxidants hinder lipid peroxidation and protect cell membranes while water soluble reacts with free redicals existing in cytosol and blood plasma (Surai, 2007). Utilisation of botanical antioxidants is correlated in control of coccidiosis because coccidial infections are associated with lipid peroxidation of mucosa of intestines and antioxidants prevent such lipid peroxidation (Naidoo et al., 2008). Coccidiosis infections promote lipid peroxidation in broilers and dietary alpha tocopherols at $316 \mathrm{mg} / \mathrm{kg}$ improved oxidant/ 
antioxidant system in victim birds (Masood et al., 2013). Antioxidant nature of ground corn showed that corn inhibited generation of lipid hydro peroxides and their secondary products. This activity was assumed due to bound hydroxyl-cinnamates like $p$-coumaric acid and ferulic acid (Bauer et al., 2013).

Antioxidant potential of corn bran. Corn husk derived arabinoxylans have been reported to possess an immunostimulatory effect, characterised by increased cytokines production and natural killer cells activity (Ogawa et al., 2005; Zhang et al., 2004). Bauer et al. (2013) reported the antioxidant potential of ground untreated corn fibre and wheat bran against lipid oxidation based on oxidative products inhibition. It was concluded that corn fibre had higher antioxidative effect at $800 \mathrm{mg} / \mathrm{kg}$ emulsion concentration which inhibited lipid hydroperoxides formation than wheat bran based on molar formulated oligosaccharides products through enzymatic treatment and methanolic extraction.

Herbal extracts and medicinal plants. Cereals derived $\beta$-glucans not only have antitussive and adipogenic activity, but they are also very important in tumor regression. Morikawa et al. (1985) conducted a study on wheat derived $\beta$-glucans. Results of their study showed about $100 \%$ increased polymorphonuclear leukocytes activity against tumor cells. Immuno-modulatory properties of oat derived $\beta$-glucans are not new, about two decades earlier a study was conducted by Estrada et al. (1997), that investigated the role of $\beta$-glucans on mice immune system. Results of their study revealed the release of TNF- $\alpha$, IFN- $\gamma$, IL-4, IL- 2 and IL- 1 from peritoneal macrophages. Oat is an important plant that has an extensive list of biological effects. It contains proteins, fats, total digestible nutrients, minerals and vitamin (thiamine). Oat is one of the beneficial grains, which is used as nutritional compound in both humans and animals. Oat can be used as an antioxidant compound due to abundant amount of two main enzymes; alcalase and tryptic that actively transform proteins into peptides and these peptides perform antioxidant activity (Hussain et al., 2002). In emergency circumstances and scarcity period oat can be used to form hay or silage. Due to this reasons it is commonly used in the diet of young animals, poultry, dairy cows and horses (Hussain et al., 2002).

In another study, Yun et al. (2003) reported that oat $\beta$-glucans were dynamically responsible for the enhance- ment of resistance in mice, against $E$. vermiformis and S. aureus. To support his idea he conducted in vitro and in vivo studies that enabled the immune system to increase phagocytic activity. Results of their study were satisfactory that fecal oocyst shedding reduced by $28 \%$ in intragastric and $39 \%$ in intraperitoneal group of mice $(\mathrm{C} 57 \mathrm{BL} / 6)$ that were initially infected with E. vermiformis as compared to control group. Moreover, oat cell wall polysaccharide, arabinoxylans and $\beta$-glucans are much important regarding health point of view. These carbohydrates are mainly effective against tumor growth and stimulate immune system (Vetvicka, 2011). Avena sativa locally known as jodar, javi or jai is an important cereal grain that has positive impact on consumer's health. Regarding their chemical structure, in recent years Havrlentova et al. (2011) reported that oat contained an important polysaccharides, $\beta$-glucans. It was concluded that one of the characteristic feature was their chemical structure $\beta, 1-4$ linkage due to which these were effective against bacteria, viruses and other pathogens. Additionally, these had anti-tumor activity and also act as free radical scavengers. Oat derived $\beta$-glucans may have some additional properties. A study was conducted by Vetvicka (2011), investigating the immunomodulatory and adipogenic activity of oat $\beta$-glucans. Moreover, it was found that these were helpful in wound healing process and also decreased the skin irritation.

Beta vulgaris. Beta vulgaris belongs to the family Chenopodiaceae and commonly known as red beet. B. vulgaris is a traditional plant in India and many countries including Pakistan and extensively used to treat as a therapeautic agent in hypertension, in diabetes and cancer due to its antioxidant properties. Roots of B. vulgaris have also been reported to be rich in antioxidant compounds (Shrishailappa et al., 2007). Its juice has been found to reduce the xenobiotic-oxidative stress in rats by rejuvenating the activity of the majority of antioxidant enzymes in liver (Kujawska et al., 2009). The active compounds present in $B$. vulgaris root include folic acid $(15.8 \mathrm{mg} / \mathrm{g})$, betacyanins and betaxanthines prevent active oxygen-induced, free radical scavengers and help in radical-mediated oxidation of biological molecules. B. vulgaris methanolic extract bears anticancerous and immunomodulatory activities (Tripathy and Pradhan, 2013).

Camellia sinensis. Camellia sinensis (green tea) is an important plant which contains natural flavonoids. 
These flavonoids are known to have antioxidant properties due to which it can be used as an excellent anticoccidial agent. Furthermore, it also contains lipids, volatiles compounds, amino acids (especially l-theanine), carbohydrates, alkaloids, carotenoids and minerals which are helpful against several diseases. It reduced fecal oocyst shedding and improved weight gain when supplemented in feed of broilers (Jang et al., 2007). Camellia sinensis also has anti-inflammatory antiproliferative anticancer antibacterial, antiviral trypanocidal agent and also showed inhibitory effect against ovine Babesia (Chen et al., 2008).

Eclipta alba. Eclipta alba which is also known as Eclipta prostate having white flowers is renowned to use as diuretic and tonic agent in treatment of various hepatic diseases. In an experiment, there was appreciable weight gain observed in broiler birds infected with Eimeria which were orally treated with Coumestans obtained from Eclipta alba at the rate of $120 \mathrm{ppm}$. It also resulted in $80 \%$ reduction in excretion of oocysts and treated birds did not show any signs of toxicity such as hepatic and muscular lesions but, at higher dose rate (180 ppm), signs of toxicity were observed in birds (Michels et al., 2011).

Aloe vera. Aloes are known medically most important plants and are used to treat many disease conditions due to their therapeutic properties. More than 360 species of aloes are identified but $A$. excelsa is well known species that has excellent anticoccidial properties, comparable with sulphachlopyrazine sodium monohydrate. Supplementation of $A$. excelsa in feed improved mean weight gain and reduced oocysts expulsion in broiler birds (Gadzirayi et al., 2005). Another important species of aloe plant is Aloe vera which is also known to have anticoccidial properties. Recently, Akhtar et al. (2012) has conducted a study to evaluate the anticoccidial and immunomodulatory effects of both aqueous and ethanolic Aloe vera extracts against coccidiosis in broiler birds and reported excellent results of Aloe vera in terms of improved immune response and increased weight gain in birds against mixed Eimeria infection. So, it can be effectively used as an immunomodulatory agent against avian coccidosis. In a study, supplementation of $A$. vera in feed showed remarkable effect in lowering gut lesions and oocyst excretion of Eimeria in faeces of broiler chickens (Yim et al., 2011).
Pinus radiata. Pinus radiata belongs to family Pinaceae which is commonly used as Monterey pine or radiata pine, has phenolic compounds due to which it has been as traditional medicinal plant in various countries such as Europe and North America. Molan et al. (2009) evaluated the in vitro efficacy of Pinus radiata aqueous extracts on prevention of oocysts sporulation of different Eimeria species. Inhibition bioassay was used to investigate the effect of PBE on the sporulation of Eimeria oocysts. The results of study revealed that incubation of unsporulated oocysts in water containing $500 \mu \mathrm{g}$ PBE per $\mathrm{mL}$ caused the prevention of sporulation of these oocysts by $28-84 \%$ as compared to control tubes. Furthermore, $12 \%$ of Eimeria oocysts showed abnormal sporocysts in size, shape and number. This study suggests that pine bark extract can be used for control of coccidiosis in broiler birds.

Ageratum conyzoides. The Asteraceae or Compositae (referred to as the aster, daisy, sunflower family) is a widespread family of flowering plants having phenolic compounds. Due to this property it has been used against ceacal coccidiosis as well as acute toxicity and given orally at dose rate $(250-300 \mathrm{mg} / \mathrm{kg}$ to $500-1000 \mathrm{mg} / \mathrm{kg})$. Reportedly casing increased weight gain and increased red blood cell count (Nweze and Obivulu, 2009).

Curcuma longa. Turmeric (Curcuma longa) is a rhizomatous herbaceous perennial plant of ginger family. Effectiveness of turmeric (C. longa) crude powder and salinomycin sodium against occurrence of coccidiosis in broiler has been reported that feed consumption, body weight gain and feed conversion ratio were better in birds supplemented with 3\% turmeric powder than untreated group (Mashhadan, 2015). Reduction in oocyst excretion and bloody diarrhoea was almost similar to the anticoccidial drug "salinomycin sodium" (Abbas et al., 2010).

Saccharum officinarum. Sugarcane (Saccharum officinarum) belonging to the genus Saccharum is one of the several species of tall perennial true grasses of warm temperate to tropical regions of South Asia Melanesia. The effectiveness of sugar cane juice and baggase were reported to counter broiler coccidiosis. Water and ethanolic extracts were used to evaluate the therapeutic efficacy of sugar cane. It showed good results in terms of reduced oocyst shedding and mortality rate was also low (Akhtar et al., 2012). Similarly, higher 
weight gain and antibodies response observed in challenged birds but relative lymphoid organ weight ratio was not significant. However, ethanolic extract was more effective than water extract (Awais et al., 2011).

Ocimum basilicum. Plants belonging to genus Ocimum have 50-150 species of shrubs and herbs found in different sub-tropical and tropical areas of Africa, Asia, South and Central America. Among these species, Ocimum basilicum has over 50 therapeutic activities and has been reported to treat large number of disease conditions. It is antiseptic, antibacterial, febrifuge and aneurostimulant (Onwurah et al., 2011). Another study was conducted to determine the effect of basil in broiler coccidiosis. The study revealed that provision of this plant extract to diseased birds showed good results with respect to feed conversion ratio, live weight gain, oocyst count and hematological parameters. However, the effect on mortality and daily feed intake were not statistically significant. This study recommended prophylactic and curative dose as 5 and $15 \mathrm{~g}$, respectively in feed and water (Onwurah et al., 2011).

Artemisia annua. Artemisia annua, also known as sweet wormwood or sweet annie. The dietary effect of Azadirachta indica and Artemisia annua has been observed on broilers performance and anticoccidial potency against $E$. tenella post infection trial. Three parameters; feed conversion ratio, average body weight gain and feed intake were focused for the evaluation of anti-coccidial activity of both plant extracts in challenged groups. Significant results were observed in orally infected bird's group with A. indica $(10 \%)$ or A. аппиа (5\%) incorporation in broiler diet (Hady and Zaki, 2012).

Thonningia sanguinea. Thonningia sanguinea is a renowned plant used as traditional medicine in African countries. Antioxidant and antiprotozoal activity of this plant has been observed against different diseases in birds. The results of study showed that dose more than $2.5 \mathrm{mg} / \mathrm{mL}$ significantly inhibited the invasion of bovine kidney cells by the sporozoites of E. necartix and E. tenella. This study demonstrated that Thonningia sanguinea can be effectively used in feed for the control of coccidiosis in broiler birds (Severin et al., 2012).

Immune response modulators. Immunostimulatory and therapeutic potential of rice bran. Rice is also known as an important immunostimulant and therapeutic agent against avian coccidiosis. Martinez et al. (2015) described the increased cytotoxic potential of natural killer (NK) cells by means of rice bran derived Arabinoxylans (MGN-3) against murine neuroblastoma. For this study, NK cells activity by means of MGN-3 addition was evaluated for their phenotypic, cytotoxic and cytometric bead potential on cultured cell lines both in vivo and in vitro, respectively for two weeks. MGN-3 showed significantly increased activity for CD25 and CD69 receptors without alteration of induced self antigens and other non-catalytic receptors. Moreover, carcinoma cells growth was also inhibited due to increased NK cells cytotoxicity. These results concluded the immunoregulatory efficacy of NK cells and their beneficial remedial application for neural carcinoma. Fang et al. (2012) elaborated the anti-inflammatory and therapeutic results of acid hydrolysed feurloylated oligosacchrides (FO) from rice bran at dose rate of $0.1-100 \mu \mathrm{g} / \mathrm{mL}$ through increased TNF- $\alpha$, IL- $1 \beta$, IL-6 and PGE2 production in RAW264.7 macrophages. Ani et al. (2013) concluded that feeding rice milling waste (RMW) improved growth rate through increased feed intake in broiler chicks. Rice is also known as an important immunostimulant and therapeutic agent against avian coccidiosis. Choi et al. (2014) reported the immunomodulatory activity of rice bran derived arabinoxylans through increased natural killer (NK) cell activity and modulated cytokine production in humans. Ghoneum et al. (2014) evaluated anticancer effects of rice bran derived arabinoxylan on cultured nonmetastatic MCF-7 human and metastatic 4T1 mice breast cancer cells. MGN-3 increased apoptosis, DNA damage and inhibition of cellular proliferation in 4T1cells. It was also concluded that rice bran derived arabinoxylans have a potent chemotherapeutic effect against metastatic breast cancer.

Ani et al. (2013) conducted a study to evaluate comparative effects of feeding rice milling waste (RMW) and Roxazyme $\mathrm{G} 2 \mathbb{R}$ enzyme on the performance of broiler chicks. Enzyme supplementation significantly reduced feed intake and improved the performance of birds in terms of average daily weight gain, protein efficiency ratio and feed cost. Enzyme supplementation significantly reduced feed intake and improved the performance of birds in terms of average daily weight gain, protein efficiency ratio and feed cost. These results 
concluded that feeding rice milling waste (RMW) improved growth rate through increased feed intake in broiler chicks. Rohman et al. (2014) described the nutritional significance of rice for diabetic patients in Asia. Besides other cereals, there is an increased dietary intake of rice due to glucose rich contents. Similarly, rice derivatives including its bran and oil in traces have also been reported to exhibit beneficial effects on health. Fat free rice bran would be resulted on further processing of rice husk. Fat free fraction of rice bran contained carbohydrates rich contents. These contents of rice derivatives exhibit their therapeutic potential against cardiac diseases and cancer in terms of hypocholestrolemic and hypoglycemic effects.

Immunomodulatory potential of barley. Yun et al. (1997) evaluated the immunostimulant potential of oat derived $\beta$-glucans $(1 \rightarrow 3,1 \rightarrow 4)$ at dose rate of $0.2 \mathrm{~mL}$ intraperitoneally in CD-1 mice in terms of increased number of macrophages in peritoneal fluid and improved survival in 3 days pre-exposure to S. aureus. Moreover, its subcutaneous dose of $0.1 \mathrm{~mL}$ or administered intragluteally $0.3 \mathrm{~mL}$ daily for 10 days in immunosuppressed and infected C57BL/6 mice with coccidiosis reduced fecal oocyst output by 23 and 34\%, as well as increased total antibody titers against sporozoites and merozoites. On the whole oat $\beta$-glucans showed immunostimulatory effects in terms of increased humoral and cellular immune responses against $E$. verniformis infection in mice.

These results suggested an immunostimulant potential of oat $\beta$-glucan against coccidiosis. Pelizon et al. (2005) evaluated the immunostimulatory effect of Sacchromyces cerevisiae derived $\beta$-glucans at dose rate of $20 \mu \mathrm{g}$ I.P. in female C57BL/ 6 mice by increased IL-12, TNF- $\alpha$ and natural killer spleen cells. $\beta$-glucans are soluble non-starch and complex polysaccharides abundantly found in bacterial, fungal, oats and barley cell walls which play their vital role in anti-microbial immunomodulation. Angeli et al. (2009) examined the mutagenicity of barley derived $\beta$-glucans in hep G2 hepatocytes at concentrations of 100 and $200 \mathrm{mg} / \mathrm{mL}$, respectively. Chan et al. (2009a) concluded the receptor based mode of action of $\beta$-glucans with respect to natural or acquired immunity in terms of lymphocytic proliferation and differentiation in reticuloendothelial system (RES). Talati et al. (2009) suggested that barley supplementation could reduce total cholesterol, triglycerides and the low density lipoprotein levels in humans. Takeshi and John (2010) described anti-inflammatory and immunostimulant potentials of $1 \mathrm{~g}$ barley derived arabinoxylans against irritable bowel syndrome (IBS) in humans in terms of improved gastrointestinal symptoms and increased NK cell activity. Samuelsen et al. (2011) concluded the low immunomodulatory response of barley derived arabinoxylans and $\beta$-glucans in vitro. Besides other cereals, barley is also known to have immunomodulatory potential against various diseases. Khoury et al. (2012) concluded the therapeutic significance of oats and barley derived $\beta$-glucans against obesity and metabolic syndrome through maintenance of enteric health in humans. Jacob and Pescatore (2012) reported the improved feeding values of barley litter through reduced intestinal viscosity while poultry farming. Gao et al. (2012) suggested that oat derived $\beta$-glucans supplementation decreased cholesterol level of serum and less enteric microbial activity with low immunomodulation in humans.

Immunomodulatory and therapeutic potential of wheat bran. Vahouny et al. (1985) evaluated an increased intestinal goblet cell secretary potential through $10 \%$ wheat bran dietary supplementation. Kruis et al. (1986) evaluated the supportive therapeutic efficacy of wheat bran in terms of superior symptomatic effect against human irritable bowel syndrome (IBS). Watzl et al. (1990) evaluated the phagocytic stimulant potential of wheat bran derived polysaccharides extract at dose rate of $10^{-2} \mathrm{mg} / \mathrm{mL}$ for human polymorphonuclear leukocytes. Roccatello et al. (1990) examined an increased in vitro cytotoxic activity of human peripheral blood mononuclear cells particularly of neutrophil chemokinesis by means of gliadin and glyc-gali at dose rate of 5 and $50 \mu \mathrm{g} / \mathrm{mL}$, respectively. Takahashi et al. (1999) examined the inhibitory effect of microfibril wheat bran on azoxy-methane at dosage rate of $20 \%$ $(\mathrm{w} / \mathrm{w})$ and $10 \mathrm{mg} / \mathrm{kg}$ against colon carcinogenesis in female CF1 mice, respectively. Neyrinck et al. (2008) suggested the therapeutic value of wheat bran derived arabinoxylans against obesity and metabolic disorders at dose rate of $10 \%$ with decreased macrophages, IL-6 and CD68 mRNA in adipose tissues in mice. Cao et al. (2011) reported the antitumor effect of wheat bran arabinoxylans in $\mathrm{S} 180$ mice by promoting cell mediated immunity with peripheral leukocytosis and increased haemopeisis. Among these cereals wheat is an important 


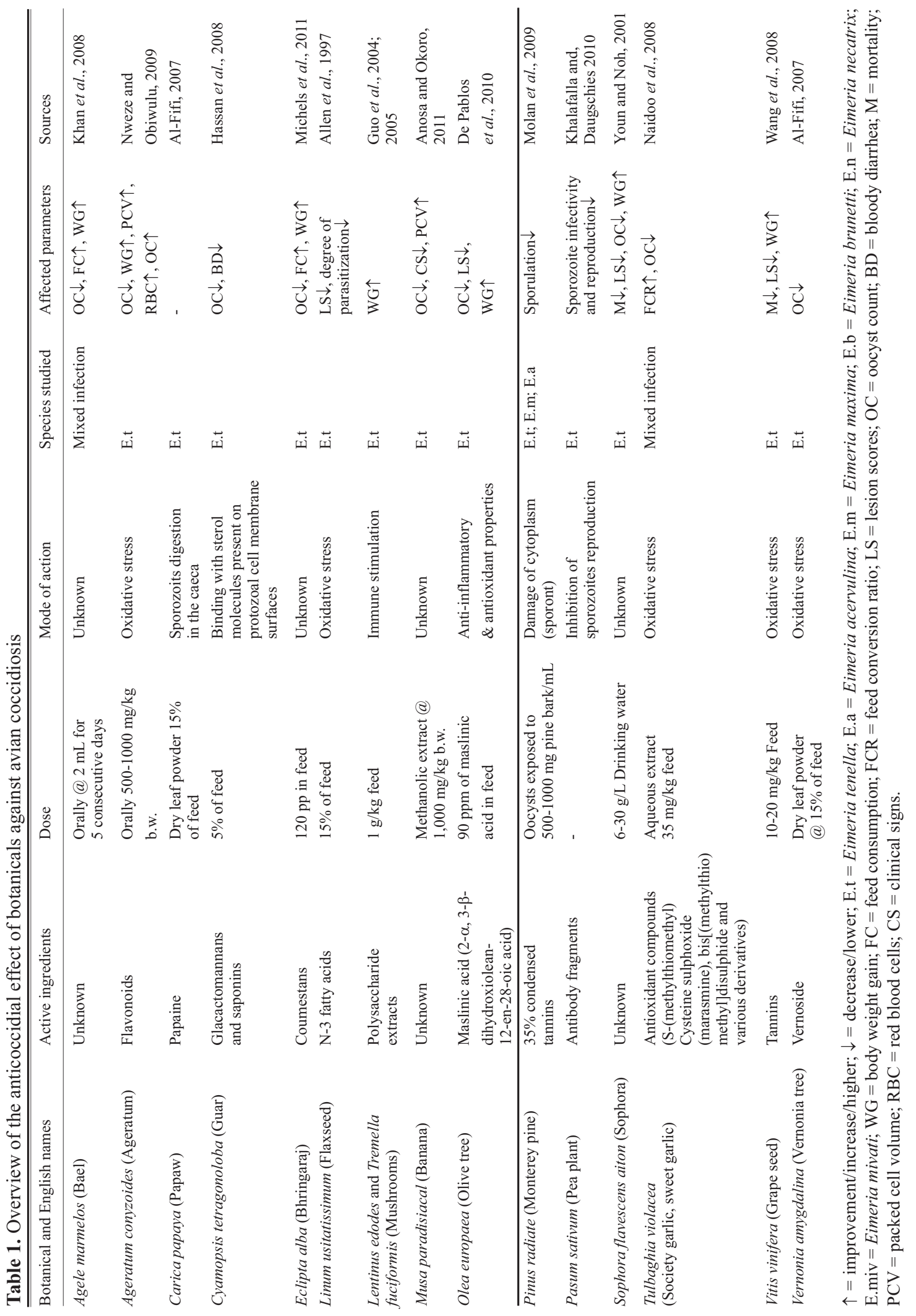


Table 2. Overview of the anticoccidial effect of herbal complexes against avian coccidiosis

\begin{tabular}{|c|c|c|c|c|c|c|}
\hline Herbal complex & Composition & Dose & $\begin{array}{l}\text { Mode of } \\
\text { action }\end{array}$ & $\begin{array}{l}\text { Species } \\
\text { studied }\end{array}$ & $\begin{array}{l}\text { Affected } \\
\text { parameters }\end{array}$ & Sources \\
\hline $\begin{array}{l}\text { Herbal } \\
\text { complex }\end{array}$ & $\begin{array}{l}\text { Uncariae ramulus cum } \\
\text { Uncis, Agrimoniae herba, Sanguisorbae } \\
\text { radix, Eclipta prostrate herba, Pulsatillae } \\
\text { radix, Sophorae feed flavescentis radix, } \\
\text { Rehmanniaea radix, Glycyrrhizae radix }\end{array}$ & $\begin{array}{l}2 \mathrm{~g} / \mathrm{mL} \\
\text { drinking } \\
\text { water \& } \\
10 \mathrm{~g} / \mathrm{kg}\end{array}$ & Unknown & $\begin{array}{l}\text { E.t } \\
\text { WG } \uparrow\end{array}$ & LS $\downarrow$ & $\mathrm{Du}$ and $\mathrm{Hu}, 2004$ \\
\hline $\begin{array}{l}\text { Muscadine } \\
\text { pomace }\end{array}$ & $\begin{array}{l}\text { By-product of the production of wine and } \\
\text { juice from Vitis rotundifolia }\end{array}$ & $\begin{array}{l}0.5-2.0 \% \\
\text { of feed }\end{array}$ & Unknown & $\begin{array}{l}\text { E.a; } \\
\text { E.m; E.t }\end{array}$ & $\begin{array}{l}\mathrm{M} \downarrow, \mathrm{LS} \downarrow \\
\mathrm{WG} \uparrow\end{array}$ & $\begin{array}{l}\text { McDougald } \\
\text { et al., } 2008\end{array}$ \\
\hline $\begin{array}{l}\text { Herbal } \\
\text { complex }\end{array}$ & $\begin{array}{l}\text { Solanum nigrum }(35 \%) \text {, Aloe vera } \\
(15 \%), \text { Moringa indica }(35 \%) \text { and } \\
\text { Mentha arvensis }(15 \%)\end{array}$ & $\begin{array}{l}10 \% \text { in feed } \\
\text { for } 7 \text { days } \\
\text { continuously }\end{array}$ & Unknown & E.t & $\begin{array}{l}\mathrm{LS} \downarrow, \mathrm{WG} \uparrow, \\
\mathrm{FCR} \uparrow\end{array}$ & $\begin{array}{l}\text { Chandrakesan } \\
\text { et al., } 2009\end{array}$ \\
\hline $\begin{array}{l}\text { Herbal } \\
\text { complex }\end{array}$ & $\begin{array}{l}\text { Allium sativum } 4 \mathrm{~g} \text {, Zingiber officinale } 6 \mathrm{~g} \text {, } \\
\text { Azadirachta indica } 3 \mathrm{~g} \text { and Berberis } \\
\text { lyceum } 10 \mathrm{~g} \text { mixed per liter drinking water }\end{array}$ & $\begin{array}{l}\text { Treated } \\
\text { water for } 14 \\
\text { days }\end{array}$ & Unknown & $\begin{array}{l}\text { Mixed } \\
\text { infection }\end{array}$ & OC $\downarrow$ & $\begin{array}{l}\text { Nidaullah } \\
\text { et al., } 2010\end{array}$ \\
\hline $\begin{array}{l}\text { Herbal } \\
\text { complex }\end{array}$ & $\begin{array}{l}\text { Azadirachta indica, Nicotiana tabacum, } \\
\text { Calotropis procera and Trachyspermum } \\
\text { ammi }\end{array}$ & $\begin{array}{l}\text { Orally }(2-6 \mathrm{~g} \\
\text { once a day) } \\
\text { for } 7 \text { Days }\end{array}$ & Unknown & E.t & $\begin{array}{l}\mathrm{M} \downarrow, \mathrm{LS} \downarrow \\
\mathrm{WG} \uparrow, \mathrm{FCR} \uparrow, \\
\mathrm{OC} \downarrow\end{array}$ & $\begin{array}{l}\text { Zaman et al., } \\
2011\end{array}$ \\
\hline
\end{tabular}

$\mathrm{LS}=$ lesion score; $\mathrm{WG}=$ weight gain; $\mathrm{FCR}=$ food consumption ratio; $\mathrm{OC}=$ oocyst count; $\mathrm{M}=$ mortality.

Table 3. Some natural products commercially available for prevention and treatment of coccidiosis

\begin{tabular}{lll}
\hline \hline Product & Ingredients & Supplier \\
\hline Avihicox & Clove and Bocconia cordata extract & Centaur \\
Nutrimin & Apple cider vinegar & Chicken lickin \\
Kocci Free & Olive leaf, mustard seed, black seed, cloves, grapefruit seed extract & Amber Technology \\
Oil of oregan & Oregan extra virgin olive oil (80\% carvacrol) & Natural factors \\
Oilis & Natural vegetal extracts & Engormix \\
Oreganico & Oregan oil and essential oils & Flyte so fancy \\
Garlic granules & Garlic & Flyte so fancy \\
Poultry Provita & Probiotics and prebiotic inulin & Vets Plus \\
CitriStim & Mannan oligosaccharides and beta glucans & ADM \\
Orego Stim & Carvacrol (82\%) and Thymol (2.4\%) & Saife vetmed \\
Herban & Etheric oils, soya oils, oregan oils & Uncle Ted Organics Ltd \\
Herb 'n' thrive & Concentrated blend of herbs and essential oils & Chicken lickin \\
Eimericox & Several essential oils & Phytosynthese/Trouw Nutrition \\
Natustat & Several essential oils and yeast cell walls & Alltech \\
Enteroguard & Garlic and cinnamon & Orffa \\
Xtract Immunocox & Spanish pepper and turmeric & Pancosma \\
Coxynil & Allium sativum Linn 15\%, Cinnamonum camphora Nees \& Eberum 15\%, & Growell India \\
& Elephantopus scaber Linn 15\%, Valeriana wallicgii DC 15\%, Sulphur dioxide 25\% & \\
Ropadiar solution & and NaCl 15\%. & Ropapharm \\
\hline \hline
\end{tabular}

immuno-modulator against various diseases. Singh et al. (2015) described the immunomodulation of potent prebiotic, xylooligosacchrides (XOS) resulting from hydrolysis of agricultural byproducts. These XOS improved gut epithelial health for microflora and regulated antioxidant activity. Akhtar et al. (2012) evaluated the 
immuno-stimulatory and anticoccidial potentials of wheat (Triticum aestivum) bran derived arabinoxylans (AXs) in chickens. These showed an improved daily weight gain, organ body weight ratio for thymus and cecal tonsils with lower oocyst count and lesion scores and higher antibody titers against sheep red blood cells.

Fungal extracts. Fungal, Sclerotinia sclerotiorum derived beta glucans are used to treat many disease conditions due to their therapeutic effects. Suzuki et al. (1989) conducted a study in mice and found that fungal derived $\beta$-glucans were responsible to modulate immune system. Higher spleen cell proliferation was noted in response to concanavalin A (T-cell mitogen) and lipopolysaccharide (B-cell mitogen) with comparison to control group of mice. Moreover, oral administration of $S$. sclerotiorum glucans also improved the function of NK (natural killer) cells and lysosomal enzyme that actively fight back against numerous pathogens. In addition to these, antitumor activity was also observed.

This study suggests that $S$. sclerotiorum derived beta glucans can be used to enhance immune system. Saccharomyces cerevisiae is an important fungus that may have immunostimulatory effect by increasing different interleukins and cytokines production. In a study, Pelizon et al. (2005) investigated that $S$. cerevisiae derived $\beta$-glucans were responsible for increasing the fungicidal and natural killer cell activity. Moreover, increased cytokine production, IL-12 and TNF- $\alpha$ was also observed. Among body's complex system one is the immune system that is broadly categorized into adaptive and innate immune system. It is proved experimentally that both these system can be modulated by $\beta$-glucans. Chan et al. (2009b), suggested that these polysaccharides initiated their response through immune receptors. These receptors included CR3 (complement receptor), TLR-2/6, Dectin-1 and activated a set of immune cells including dendritic cells, monocytes, neutrophils, NK cells and macrophages. These polysaccharides with specific linear backbone $1 \rightarrow 3$ betaglycosidic chain could not be digested orally. Some beta glucans were initially internalized by macrophages and then fragmented inside the cells. After that these fragmented $\beta$-glucans were released and eventually picked up by other immune cells. Moreover, $\beta$-glucans with variable branching patterns and sizes had different immune potency.
In recent years, an experiment was performed by Mahdi and Al-Abass (2012), and they concluded that $S$. cerevisiae derived $\beta$-glucans had immunomodulatory effect in broilers. Results of their study showed that administered group had faster clearance rate of carbon particles than untreated control group. The fast clearance rate might be due to increased phagocytic activity. Moreover, it was also observed that $\beta$-glucans administered group had improved their body weight gain than control group. Conclusions of their study suggested that $\beta$-glucans can be used to improve weight gain in broilers.

\section{Conclusion}

Over a time, anticoccidial drugs development has increased in response to the urgent need to control avian coccidiosis. Today, we have many strategies available, many of which currently widely used in chickens farms. Moreover, new alternatives are emerging, as is the case with anticoccidial is obtained from plants, fungal or microorganisms. One of advantages of using natural extracts is the lower risks of developing resistance, such as that observed with chemical drugs. It is widely known that availability of raw materials and cost of production could be high in the development of natural extracts alternatives. However, the cost is well worth it if we consider that these alternatives are friendly to the environment, producers and consumers.

\section{References}

Abbas, R.Z., Colwell, D.D., Gilleard, J. 2012. Botanicals an alternative approach for the control of avian coccidiosis. International Journal of Agriculture and Biology, 68: 203-215.

Abbas, R.Z., Iqbal, Z., Khan, M.N., Zafar, M.A., Zia, M.A. 2010. Anticoccidial activity of Curcuma longa in broilers. Brazilian Archives of Biology and Technology, 1: 63-67.

Ahmad, F., Haq, A.U., Ashraf, M., Abbas, G., Siddiqui, M.Z. 2011. Effect of different light intensities on the production performance of broiler chickens. Pakistan Veterinary Journal, 31: 203-206.

Ahmad, F., Haq, A.U., Ashraf, M., Hussain, M.J., Siddiqui, M.Z. 2010. Production performance of White Leghorn hens under different lighting regimes. Pakistan Veterinary Journal, 30: 21-24.

Akhtar, M., Tariq, A.F., Awais, M.M., Iqbal, Z., Muhammad, F., Shahid, M., Sawicka, E.H. 2012. 
Studies on wheat bran Arabinoxylan for its immunostimulatory and protective effects against avian coccidiosis. Carbohydrate Polymerase, 90: 333339.

Al-Fifi, Z.I.A. 2007. Effect of leaves extract of Carica papaya, Vernonia amigdalina and Azadirachta indica on the coccidiosis in free-range chickens. Asian Journal of Animal Sciences, 1: 26-32.

Allen, P.C., Danforth, H., Stitt, P.A. 2000. Effects of nutritionally balanced and stabilized flax meal-based diets on Eimeria tenella infections in chickens. Poultry Science, 79: 489-492.

Allen, P.C., Danforth, H.D., Levander, O.A. 1997. Interaction of dietary flaxseed with coccidia infections in chickens. Poultry Science, 76: 822827.

Angeli, J.P.F., Ribeirob, L.R., Angeli, J.L.F., Mantovani, M.S. 2009. Protective effects of $\beta$-glucan extracted from barley against benzopyrene-induced DNA damage in hepatic cell HepG2. Experimental and Toxicologic Pathology, 61: 83-89.

Ani, A.O., Kalu, I., Ugwuowo, L.C., Lloh, E.A. 2013. Dietary effect of rice milling waste and supplementary enzyme on performance of broiler chicks. African Journal of Biotechnology, 12: 5326-5332.

Anosa, G.N., Okoro, O.J. 2011. Anticoccidial activity of the methanolic extract of Musa paradisiaca root in chickens. Tropical Animal Health and Production, 43: $245-248$.

Awais, M.M., Akhtar, M., Muhammad, F., Haq, A.U., Anwar, M.I. 2011. Immunotherapeutic effects of some sugar cane (Saccharum officinarum L.) extracts against coccidiosis in industrial broiler chickens. Experimental Parasitology, 128: 104110.

Bauer, J.L., Piayda, B.H., Stockman, H., Schwarz, K. 2013. Antioxidant activities of corn fiber and wheat bran and derived extracts. Food Science Technology, 50: $132-138$.

Cao, L., Liu, X., Qian, T., Sun, G., Guo, Y., Chang, F., Zhou, S., Sun, X. 2011. Antitumor and immunomodulatory activity of arabinoxylans: A major constituent of wheat bran. International Journal of Biological Macromolecules, 48: 160-164.

Chan, G.C.F., Chan, W.K., Sze, D.M.Y. 2009a. The effects of beta-glucan on human immune and cancer cells. Journal of Hematology and Oncology,
2: 25-36.

Chan, G.C.F., Wing, K.C., Daniel, M.S. 2009b. The effects of $\beta$-glucan on human immune and cancer cells. Journal of Hematology and Oncology, 1: $1-11$.

Chandrakesan, P., Muralidharan, K., Kumar, V.D., Ponnudurai, G., Harikrishnan, T.J., Rani, K.S.V.N. 2009. Efficacy of a herbal complex against caecal coccidiosis in broiler chickens. Veterinary Archives, 79: 199-203.

Chapman, H.D. 2000. Practical use of vaccines for the control of coccidiosis in the chicken. World's Poultry Science Journal, 56: 7-20.

Chen, H., Zhang, M., Qu, Z., Xie, B. 2008. Antioxidant activities of different fractions of polysaccharide conjugate from green tea (Camellia sinensis). Food Chemistry, 106: 559-563.

Choi, J.Y., Paik, D.J., Kwon, D.Y., Park, Y. 2014. Dietary supplementation with rice bran fermented with Lentinus edodes increases interferon- $\alpha$ activity without causing adverse effects: a randomized, double-blind, placebo-controlled, parallel-group study. Nutritional Journal, 13: 35.

Dalloul, R.A., Lillehoj, H.S. 2006. Poultry coccidiosis recent advancements in control measures and vaccine development. Experimental Research Vaccines, 5: 143-163.

Dalloul, R.A., Lillehoj, H.S., Shellem, T.A., Doerr, J.A. 2003. Intestinal immunomodulation by vitamin A deficiency and lactobacillus-based probiotic in Eimeria acervulina infected chickens broiler. Avian Diseases, 47: 1313-1320.

De Pablos, L.M., dos Santos, M.F., Montero, E., GarciaGranados, A., Parra, A., Osuna, A. 2010. Anticoccidial activity of maslinic acid against infection with Eimeria tenella in chickens. Parasitology Research, 107: 601-604.

$\mathrm{Du}, \mathrm{A} ., \mathrm{Hu}, \mathrm{S} .2004$. Effects of a herbal complex against Eimeria tenella infection in chickens. Journal of Veterinary Medicines B. Infectious Diseases and Veterinary Public Health, 51: 194-197.

Estrada, A., Yun, C.H., Andrew, V.K., Bing, L., Shirley, H., Bernard, L. 1997. Immunomodulatory activities of oat $\beta$-glucan in vitro and in vivo. Microbiology and Immunology, 41: 991-998.

Etuk, E.B. 2010. Survey of the distribution of coccidiosis in poultry farm in Akwa Ibom State, Nigeria. 
Journal of Parasitology and Infectious Diseases, 5: 18-21.

Fang, H.Y., Chen, Y.K., Chen, H.H., Lin, S.Y., Fang, Y.T. 2012. Immunomodulatory effects of feruloylated oligosaccharides from rice bran. Food Chemistry, 134: 836-840.

Farnsworth, N.R. 1999. The role of ethnopharmacology in drug development. In: Bioactive Compounds from Plants. D. J. Chadurich and J. Marsh (eds.), Ciba Foundation Symposium 185-Ethnobotany and search for New Drugs, 154: 2-11., Wiley International On line, New York, USA.

Gadzirayi, C.T., Mupangwa, J.F., Mutandwa, E. 2005. Effectiveness of Aleo excelsa in controlling coccidiosis in broilers. The Journal of Sustainable Development in Africa, 7: 321-327.

Gao, K., Rosenberg, J., Hinkova, A., Sturdik, E. 2012. Pilot study of the effect of acemannan in cats infected with feline immunodeficiency virus. Veterinary Immunology and Immunopathology, 25: 272-289.

Ghatak, S.B., Panchal, S.J. 2012. Investigation of the immunomodulatory potential of oryzanol isolated from crude rice bran oil in experimental animal models. Phytotherapy Research, 26: 1701-1708.

Ghoneum, M., Din, N.K.B.E., Ali, D.A., Dein, M.A. E. 2014. Modified Arabinoxylan from rice bran, MGN-3/Biobran, sensitizes metastatic breast cancer cells to Paclitaxel in vitro. Anticancer Research, 34: 81-88.

Ghoneum, M., Jewett, A. 2000. Production of tumor necrosis factor-alpha and interferon-gamma from human peripheral blood lymphocytes by MGN-3, a modified arabinoxylan from rice bran and its synergy with interleukin-2 In Vitro. Cancer Detection and Prevention, 24: 314-324.

Ghoneum, M. 1998. Enhancement of human natural killer cell activity by modified arabinoxylan from rice bran (MGN-3). International Journal of Immunotherapy, 14: 89-99.

Guo, F.C., Kwakkel, R.P., Williams, B.A., Suo, X., Li, W.K., Verstegen, M.W. 2005. Coccidiosis immunization: effects of mushroom and herb poly-saccharides on immune responses of chickens with Eimeria tenella. Avian Diseases, 4: 70-73.

Guo, F.C., Kwakkel, R.P., Williams, B.A., Paramentier, H.K., Li, W.K., Yang, Z.Q., Verstegen, M.W. 2004.
Effects of mushroom and herb polysaccharides on cellular and humoral immune responses of E. tenella-infected chickens. Poultry Science, 83: 1124-1132.

Hady, M.M., Zaki, M.M. 2012. Efficacy of some herbal feed additives on performance and control of cecal coccidiosis in broilers. APCBEE Procedia, 4: 163-168.

Hassan, S.M., El-Gayar, A.K., Cadwell, D.J., Bailey, C.A., Cartwright, A.L. 2008. Guar meal ameliorates Eimeria tenella infection in broiler chicks. Veterinary Parasitology, 157: 133-138.

Havrlentova, M., Petrulakova, Z., Burgarova, A., Gago, F., Hlinkova, A., Sturdik, E. 2011. Cereal $\beta$-glucans and their significance for the preparation of functional foods-A Review. Journal of Food Science, 29: $1-14$

Hussain, A., Khan, S., Mufti, M.U., Bakhsh, A. 2002. Introduction and use of oats cultivars in Pakistan. In: Proceedings of "5th TAPAFON (Temperate Asia Pasture and Fodder Network) Meeting/Conference held at Renewable Natural Resources Research Center, Bajo (Wangdue-Bhutan), pp. 159-166.

Jacob, J.P., Pescatore, A.J. 2012. Using barley in poultry diets. Journal of Applied Poultry Research, 4: 915-940.

Jang, I.J., Jun, M., Lillehog, H.S., Dalloul, R.A., Kong, I.K., Kim, S., Min, W. 2007. Anticoccidial effect of green tea-based diets against Eimeria maxima. Veterinary Parasitology, 144: 172-175.

Khalafalla, R.E., Daugschies, A. 2010. In vivo evaluation of anticoccidial effect of antibody fragments expressed in pea (Pasum sativum) on Eimeria tenella sporozoites. Parasitology Research, 107: 983-986.

Khan, M.A., Younas, M., Khan, I., Abbas, R.Z., Ali, M. 2008. Comparative efficacy of some herbal and homeopathic preparations against coccidiosis in broilers. International Journal of Agriculture and Biology, 10: 358-360.

Khoury, D., Cuda, C., Luhovyy, B.L., Anderson, G.H. 2012. Beta glucan: Health benefits in obesity and metabolic syndrome. Journal of Nutrition Metabolism, 28 pp., doi:10.1155/2012/851362.

Kruis, W., Weinzierl, M., Holl, J., Schussler, P. 1986. Comparison of the therapeutic effect of wheat bran, mebeverine and placebo in patients with the irritiable 
bowel syndrome. Digestion, 34: 196-201.

Kujawska, M., Ignatowicz, E., Murias, M., Ewertowska, M., Mikorajczyk, K., Jodynis-Liebert, J. 2009. Protective effect of red beet root against carbon tetrachloride and $\mathrm{N}$-nitrosodiethylamine induced oxidative stress in rats. Journal of Agriculture and Food Chemistry, 57: 2570-2575.

Lorrain, B., Dangles, O., Genot, C., Dufour, C. 2010. Chemical modeling of heme-induced lipid oxidation in gastric conditions and inhibition by dietary polyphenols. Journal of Agriculture and Food Chemistry, 58: 676-683.

Mahdi, N.R., Al-Abass, H.A. 2012. Study the immunomodulatory effects of beta-glucan in broiler chickens. Veterinary Science Conference, 11: 64-71.

Mashhadani, H.E.A. 2015. Effect of different levels of Turmeric (Curcuma longs) supplementation on broiler performance, carcess characteristic and bacterial count. Egyptian Poultry Science Journal, 35: $25-39$.

Martinez, A.P., Valentin, J., Fernandiz, L., Jimenez, E.H., Collazo, E.L., Zerbez, P., Schworer, E., Nunez, F., Martin, I.G., Sallis, H., Diaz, M.A., Handgretinger, R., Pfeiffer, M.M. 2015. Arabinoxylan rice bran (MGN-3/Biobran) enhances natural killer cell-mediated cytotoxicity against neuroblastoma in vitro and in vivo. Cytotherapy, 17: 601-612.

Masood, S., Abbas, R.Z., Iqbal, Z., Mansoor, M.K., Sindhu, Z.D., Zia, M.A., Khan, J.A. 2013. Role of natural antioxidants for the control of coccidiosis in poultry. Pakistan Veterinary Journal, 33: 401407.

Mcdougald, L.R., Hofacre, C., Mathis, G., Fuller, L., Hargrove, J.L., Greenspan, P., Hartle, D.K. 2008. Enhancement of resistance to coccidiosis and necrotic enteritis in broiler chickens by dietary muscadine pomace. Avian Diseases, 52: 646-651.

Michels, M.G., Bertolini, L.C.T., Esteves, A.F., Moreira, P., Franca, S.C. 2011. Anticoccidial effects of coumestans from Eclipta alba for sustainable control of Eimeria tenella parasitosis in poultry production. Veterinary Parasitology, 177: 55-60.

Molan, A.L., Zhuojian, L.I.U., Shampa, D.E. 2009. Effect of pine bark (Pinus radiata) extracts on sporulation of coccidian oocysts. Folia Parasitologica, 56: 1-5.

Morikawa, K., Reiko, T., Masatoshi, Y. 1985. Induction of tumoricidal activity of polymorphonuclear leukocytes by a linear $\beta$-1,3-d-glucan and other immunomodulators in murine cells. Cancer Research, 45: 1496-1501.

Naidoo, V., McGaw, L.J., Bisschop, S.P., Duncan, N., Eloff, J.N. 2008. The value of plant extracts with antioxidant activity in attenuating coccidiosis in broiler chickens. Veterinary Parasitology, 153: 214-219.

Neyrinck, A.M., Backer, F.D., Cani, P.D., Bindels, L.B., Stroobants, A., Portetelle, D., Delzenne, N.M. 2008. Immunomodulatory properties of two wheat bran fractions - aleurone-enriched and crude fractions - in obese mice fed a high fat diet. International Immunopharmacology, 8: 1423-1432.

Nidaullah, H., Durrani, F.R., Ahmad, S., Jan, I.U., Gul, S. 2010. Aqueous extract from different medicinal plants as anticoccidial, growth promotive and immunostimulant in broilers. ARPN Journal of Agricultural and Biological Science, 5: 53-59.

Nogueira, V.A., Franca, T.N., Peixoto, P.V. 2009. Ionophore poisoning in animals. Pesquisa Veterinária Brasileira, 29: 191-197.

Nweze, N.E., Obiwulu, I.S. 2009. Anticoccidial effects of Ageratum conyzoides. Journal of Ethnopharmacology, 122: 6-9.

Ogawa, K., Takeuchi, M., Nakamura, N. 2005. Immunological effects of partially hydrolyzed arabinoxylan from corn husk in mice. Bioscience, Biotechnology and Biochemistry, 69: 19-25.

Oka, T., Fujimoto, M., Nagasaka, R., Ushio, H., Hori, M., Ozaki, H. 2010. Cycloartenyl ferulate, a component of rice bran oil-derived $\gamma$-oryzanol, attenuates mast cell degranulation. Phytomedicine, 17: 152156

Onwurah, F.B., Ojewola, G.S., Akomas, S. 2011. Effect of Basil (Osimum basilicum L.) on coccidial infection in broiler chicks. Academic Research International, 1: 439-442.

Park, H.Y., Yu, A.R., Choi, I.W., Hong, H.D., Lee, K.W., Choi, H.D. 2013. Immunostimulatory effects and characterization of a glycoprotein fraction from rice bran. International Immunopharmacology, 17: 191-197.

Patwardhan, B., Gautam, M. 2005. Botanical immunodrugs: scope and opportunities. Drug, Discovery Therapy, 10: 495-501. 
Pelizon, A.C., Kaneno, R., Soares, A.M., Meira, D.A., Sartori, A. 2005. Immunomodulatory activities associated with $\beta$-glucan derived from Saccharomyces cerevisiae. Physiology Research, 54: 557-564.

Roccatello, D., Coppo, R., Cavalli, G., Piccoli, G., Amprimo, M.C., Guerra, M.G., Amore, A., DiMauro, C., Quattrocchio, G., Cacace, G. 1990. Wheat protein antigens and effector cells of a specific immunity. Journal of Clinical Laboratory of Immunology, 31: 167-173.

Rohman, A., Helmiyati, S., Hapsari, S., Setyaningrum, D.L. 2014. Rice in health and nutrition, mini review. International Food Rearch Journal, 21: 13-24.

Saima, K., Jabbar, M.Z.U., Mehmood, M.A., Abbas, A., Mahmood, A. 2010. Effect of lysine supplementation in low protein diets on the performance of growing broilers. Pakistan Veterinary Journal, 30: 17-20.

Samuelsen, A.B., Rieder, A., Grimmer, S., Michaelsen, T.E., Knutsen, S.H. 2011. Immunomodulatory activity of dietary fiber: Arabinoxylan and mixedlinked $\beta$-glucan isolated from barley show modest activities in Vitro. International Journal of Molecular Science, 12: 570-587.

Severin, K.K., Alassane, T., Karamoko, O., Joseph, D., David, N.J. 2012. In vitro anticoccidial activity of Thonningia sanguinea extract on Eimeria tenella and Eimeria necatrix sporozoites cells. African Microbiology Research, 6: 6247-6251.

Shrishailappa, B., Santhoshkumar, H., Senthilkumar, N., Raghu, C.H. 2007. Journal of Pharmacology, 103: 354-359.

Singh, R.D., Banerjee, J., Arora, A. 2015. Prebiotic potential of oligosaccharides: A focus on xylan derived oligosaccharides. Bioactive Carbohydrates and Dietary Fibre, 5: 19-30.

Surai, P.F. 2007. Natural antioxidants in poultry nutrition: New developments. $16^{\text {th }}$ European Symposium on Poultry Nutrition, Strasbourg, France, pp. 669-676.

Suzuki, I., Koichi, H., Naohito, O., Hideki, T., Toshiro, Y. 1989. Immunomodulation by orally administered beta-glucan in mice. International Journal of Immunopharmacology, 11: 761-769.

Tacconelli, E. 2009. Antimicrobial use: Risk driver of multidrug resistant microorganisms in health care settings. Current Opinion Infectious Diseases, 22: 352-358.
Takahashi, T., Satou, M., Watanabe, N., Sakaitani, Y., Takagi, A., Uchida, K., Ikeda, M., Moriyama, R., Matsumoto, K., Morotomi, M. 1999. Inhibitory effect of microfibril wheat bran on azoxymethane induced colon carcinogenesis in CF1 mice. Cancer Letters, 141: 139-146.

Takeshi, K.M.S., John, T. 2010. The anti-inflammatory and immunomodulatory effects of rbac (rice bran Arabinoxylan compounds) on irritable bowel syndrome. The $50^{\text {th }}$ Annual Meeting of the Japanese Society of Gastroenterology. Journal of Gastroenterology, 105: Special issue.

Talati, R., Baker, W.L., Pabilonia, M.S., White, C.M., Coleman, C.I. 2009. The effects of barley-derived soluble fiber on serum lipids. Annals of Family Medicine, 7: 157-163.

Tripathy G., Pradhan, D. 2013. Evaluation of in vitro antiproliferative and in vivo Immunomodulatory activity of Beta vulgaris. Asian Journal of Pharmacology and Clinical Research, 6: 127-130.

Vahouny, G., Truc, L., Ifrim, I. 1985. Stimulation of intestinal cytokinetics and mucin turnover in rats fed wheat bran or cellulose. American Journal of Clinical and Nutrition, 41: 895-900.

Vetvicka, V. 2011. Glucan-immunostimulant, adjuvant, potential drug. Journal of Clinical Oncology, 2: 115-119.

Wang, M.L., Suo, X., Gu, J.H., Zhang, W.W., Fang, Q., Wang, X. 2008. Influence of grape seed proanthocyanidin extract in broiler chickens: effect on chicken coccidiosis and antioxidant status. Poultry Science, 87: 2273-2280.

Watzl, K., Feyll, H.R., Ruhl, H., Leitzmann, C. 1990. Impact of wheat on the non-specific immune response of man.II. whole wheat. Nutrition Research, 10: $137-143$.

Yim, D., Kang, S.S., Kim, D.W., Kim, S.H., Lillehoj, H.S., Min, W. 2011. Protective effects of Aloe verabased diets in Eimeria maxima infected broiler chickens. Experimental Parasitology, 127: 322-325.

Youn, H.J., Noh, J.W. 2001. Screening of the anticoccidial effects of herb extracts against Eimeria tenella. Veterinary Parasitology, 96: 257-263.

Yun, C.H., Estrada, A., Andrew, V.K., Byung, C.P., Bernard, L. 2003. L-glucan extracted from oat, enhances disease resistance against bacterial and parasitic infections. Immunology and Microbiology, 
35: 67-75.

Yun, C.H., Estrada, A., Kessel, V., Gajadhar, A.A., Redmond, M.J., Laarveld, B. 1997. Oat glucan enhances resistance to Eimeria vermiformis infection in immunosuppressed mice. Internatinal Jouranl of Parasitology, 27: 329-337.

Zaman, M.A., Iqbal, Z., Abbas, R.Z., Khan, M.N. 2012. Anticoccidial activity of herbal complex in broiler chickens challenged with Eimeria tenella. Journal of Parasitology, 139: 237-243.

Zaman, M.A., Iqbal, Z., Abbas, R.Z., Khan, M.N. 2011. Anticoccidial activity of herbal complex in broiler chickens challenged with Eimeria tenella. Parasitology, 139: 237-243.

Zhang, P., Jennifer, L.W., Arun, K.B., Kristin, M.B., John, A.P., Roy, L.W. 2004. Effects of Arabinoxylans on activation of murine macrophages and growth performance of broiler chickens. Cereal Chemistry, 81: 511-514.

Zhou, S., Liu, X., Guo, Y., Wang, Q., Peng, D., Cao, L. 2010. Comparison of the immunological activities of arabinoxylans from wheat bran with alkali and xylanase-aided extraction. Carbohydrate Polymers, 81: 784-789. 